\title{
Ocular Surface Changes in Patients with Thyroid Eye Disease: An Observational Clinical Study
}

\author{
Ibrahim Y Allam' \\ Sihem Lazreg ${ }^{2}$ \\ Mohamed Shafik Shaheen' \\ Mohamed Fahmy Doheim' \\ Mai A Mohammed' \\ 'Ophthalmology Department, Faculty of \\ Medicine, Alexandria University, Alexandria, \\ Egypt; ${ }^{2}$ Cabinet Ophtalmologie, Alger \\ Centre, Algiers, Algeria
}

Background: This study aimed to compare ocular surface parameter changes in active and inactive thyroid eye disease (TED) patients and controls.

Methods: This is an observational clinical study that included 60 eyes divided into three groups following clinical activity score (CAS) assessment. The first group (Group A) comprised 20 eyes with active TED (CAS score $\geq 3 / 7$ ), while the second group (Group B) comprised 20 eyes with inactive TED (CAS score <3/7) and the third group (Group C) comprised 20 eyes of controls without dry eye manifestations. The palpebral fissure height, degree of proptosis, degree of lagophthalmos, ocular surface disease index (OSDI), Schirmer test without anesthesia, corneal fluorescein staining (CFS), non-invasive tear break-up time (NITBUT), tear meniscus height (TMH), lipid layer thickness (LLT), meiboscore, meibomian gland dysfunction (MGD), and thyroid antibodies were assessed and data were compared between study participants.

Results: The mean OSDI was $40.0 \pm 5.80$ in Group A, which significantly differed from Group B with a mean of $26.5 \pm 5.10(\mathrm{p}=0.02)$. There were significant differences between the two groups regarding palpebral fissure height ( $p=0.02)$, amount of proptosis $(p=0.008)$, and degree of lagophthalmos $(\mathrm{p}=0.001)$. Similarly, active TED patients had more decreased tear secretion than inactive TED patients $(\mathrm{p}=0.012)$. Moreover, active TED patients showed a significant increase in Meibomian gland loss areas in both upper and lower eyelids compared with inactive TED patients $(\mathrm{p}=0.001)$. Corneal fluorescein staining also revealed a statistically significant difference between the studied groups $(\mathrm{p}=0.0001)$.

Conclusion: This study showed differences regarding ocular surface parameter changes between both active and inactive TED and compared to controls. Further studies are needed to confirm these results.

Keywords: thyroid eye disease, dry eye disease, ocular surface, thyroid antibodies

\section{Introduction}

Thyroid eye disease (TED) is related to a systemic autoimmune process that is usually manifested by edema, redness in the periorbital tissues in addition to conjunctiva, upper eyelid retraction, and proptosis. ${ }^{1,2}$ Ocular surface damage with dry eye disease (DED) stands among the most common findings that usually appear before classic eye signs, with the prevalence rate of DED in TED reaching up to $65.2 \%{ }^{1,3,4}$ Although the correlation is well-documented, the mechanism explaining the relationship between TED and DED is not fully established. The increase in the width of palpebral fissure in addition to the alterations of the lid caused by TED has been implicated in disrupting the homeostasis of the ocular surface. This results in corneal exposure, accelerated tear evaporation via tear film instability, and high tear
Correspondence: Ibrahim Y Allam Ophthalmology Department, Faculty of Medicine, Alexandria University, El Maram Building, $3^{\text {rd }}$ Mostafa Kamel St., Smouha, Alexandria, 21615 , Egypt

Tel +201001233126

Fax +2034210443

Email ibrahimallam2007@gmail.com 
osmolarity. ${ }^{5,6}$ With progression of the disease, ocular surface inflammation progresses, starting a vicious cycle to DED. ${ }^{7}$ Nevertheless, the ocular surface tissues also may be direct sites for autoantibodies and inflammation occurrence in the retrobulbar space. ${ }^{1,8}$ In addition to the abnormal ocular surface, the aqueous tear production may decrease due to the ongoing inflammatory process of TED. ${ }^{9}$ In addition, there is a direct involvement of the lacrimal gland in the pathological mechanism of the dry eye syndrome in thyroid patients ${ }^{10,11}$ and lacrimal glands were found to be enlarged in patients with hyperthyroid TED patients. ${ }^{12}$ The lacrimal gland additionally expresses the receptors of thyroid-stimulating hormones, documented by immunohistochemical studies, which makes it a potential site for the autoantibodies in TED and potentially contributes to the impairment of lacrimal gland and DED. ${ }^{10}$ Studies using cornea laser scanning confocal microscopy showed an elevated number of activated keratocytes and reduced the density of corneal nerve fiber in active TED, ${ }^{13,14}$ a pathology that affects the neural feedback and adds more stress on the ocular surface.

Moreover, meibomian gland dysfunction (MGD), which is known to be an important cause of dry eye that causes elevated evaporation of the tear film, may share the pathogenesis of DED in these patients. Blinking would apply shearing force to the glands, which would reduce tear viscosity, making their lipid content easier to eject. In TED patients, the incomplete blinking due to proptosis and eyelid retraction can cause obstructive MGD that can be one of the several factors causing dry eye in TED patients. ${ }^{15}$ The aforementioned pathophysiologic mechanisms lead to ocular surface manifestations in $45-85 \%$ of patients with TED. ${ }^{16}$ In a study that assessed ocular tear in cases with thyroid disorders, a high level of eye dryness was found. ${ }^{17}$

The disease has an inflammatory, active phase that can have rapidly worsening symptoms and signs, usually subsiding over 1 to 2 years (range $=6$ months to 5 years), which gives way to a static plateau phase that is the fibrotic, inactive phase. In this phase, gradual improvement of inflammatory signs can be seen. These phases can be plotted graphically for each patient along a Rundle's curve that describes the natural history of the disease. $^{18}$

Conjunctiva impression cytology ${ }^{19,20}$ and tear fluid proteomics $^{21,22}$ prove that the higher damage of the ocular surface in active TED compared to the inactive stage is related to mechanical factors in addition to orbit inflammation. This is the multifactorial etiology of dry eye and it is the clinical picture in TED patients who experience variable impacts during periods of activity and quiescence. Therefore, this study aimed to evaluate and compare the symptoms and ocular surface parameter changes in active and inactive TED patients and age-matched controls.

\section{Methods}

\section{Participants}

This was an observational clinical study that included 60 eyes divided into three groups following clinical activity score (CAS) assessment. The first group (Group A) included 20 eyes with active TED (CAS score $\geq 3 / 7$ ), the second group (Group B) included 20 eyes with inactive TED (CAS score <3/7), and the third group (Group C) included 20 eyes of age-matched healthy controls. The tenets of the Declaration of Helsinki were followed. We obtained informed consent from the participants after explaining the treatment options, the risks and benefits of each procedure, and gained approval of the study from the ethics committee of Alexandria Faculty of Medicine.

Diagnosis of TED was made on the basis of 2 of the following 3 criteria: (1) immune-related thyroid dysfunction (Grave's hyperthyroidism, Hashimoto thyroiditis, circulating thyroid antibody) was present; (2) an imaging study revealed fusiform enlargement of at least one of the extraocular muscles, and/or (3) patients had at least 1 of the following typical orbital signs: upper eyelid retraction, exophthalmos, typical restrictive strabismus, fluctuating lid edema, or chemosis/caruncular edema. ${ }^{23}$ The following exclusion criteria were applied: being younger than 20 or older than 60 , presence of any uncontrolled systemic diseases, rheumatic disease that may cause dry eye, including Sjögren syndrome, previous ocular surgery, use of contact lenses, eyelid not able to be everted, and previous orbital radiotherapy.

\section{Clinical Assessment}

Proptosis was assessed via a Hertel exophthalmometer (Handaya, Tokyo, Japan). In addition, lid retraction was considered as a palpebral fissure height of more than $7 \mathrm{~mm}$ with exposure for the upper sclera. The disease activity in cases with TED was scored following the CAS clinical criteria reported by Mourits et al. ${ }^{24}$ This score consists of seven items: pain at rest, painful eye movement, red conjunctiva, red eyelid, chemosis, swelling of the eyelid, and swollen caruncle. 
For Schirmer I test without anesthesia, regular Schirmer stripes (IO SchirmeEye Care Products, Delhi, India) were folded and gently placed at the temporal angle as far as practicable over the lower lid edge. During the procedure the patient was advised to hold her eyes closed. The strips were calculated using the millimetre scale of each strip after five minutes of wetting. For corneal fluorescent staining (CFS), the area (A) and density (D) classifications for corneal fluorescein staining were considered to be the main assessments of dry eye. The AD classification was done using the scale reported by Miyata et al. ${ }^{25}$ An ocular surface analyzer (OSA) used an SBM Sistemi machine to work out the average noninvasive tear break-up times (NITBUT). This measures the number of seconds between one complete blinking and the appearance of the first discontinuity in the tear film. We measured tear meniscus height (TMH) and lipid layer thickness: interferometric analysis of the lipid layer in the tear film. For the meiboscore, we assessed meibomian gland loss area through infrared meibography. Partial or complete loss of the MGs was scored using the following grades for each eyelid: ${ }^{26} 0=$ no loss of MGs; $1=$ area loss of less than one-third of the total MG area; $2=$ area loss of between one-third and two-thirds; and $3=$ area loss of more than two-thirds. ${ }^{26}$ Each eye of TED patients was assessed for signs of MG dysfunction, including plugging orifices of MG, irregularities in lid margin, vascular engorgement, thickening, and shift in mucocutaneous junction. ${ }^{27}$ Eyes having any of the aforementioned signs were considered sign-positive for MG dysfunction. DED was set as a diagnosis when the following criteria were met: (1) manifestations such as dryness, pain foreign body sensation, and blurred vision, (2) TBUT lower than 10 seconds, and (3) Schirmer test I lower than $10 \mathrm{~mm}$ after 5 minutes. Subjective scoring of all patients was done using the Ocular Surface Disease Index (OSDI). An OSDI score of 12 indicated a normal healthy eye, a score of 13-22 indicated a mild dry eye condition, 23-32 was regarded as a sign of a moderate dry eye condition, and a score of more than 33 was considered a sign of severe eye dryness. $^{28}$

Following the OSDI questionnaire, noninvasive testing for tear meniscus height (TMH), non invasive tear breakup time (NITBUT), lipid layer thickness (LLT) and meibography parameters were done prior to invasive testing, including Schirmer test I and CFS.

Free T3, T4, TSH, thyroid peroxidase antibody (TPO), thyroid stimulating hormone receptor antibodies
(TSHRAb), and thyroglobulin antibody (TGAb) were evaluated.

Upper limit values of thyroid antibodies were 0-34 IU/ $\mathrm{mL}$ TPO Ab, 0-115 IU/mL for TG Ab, and 0-1.75 IU/mL for TSHR Ab.

\section{Statistical Analysis of the Data}

Data were analyzed using the IBM SPSS software package version 24.0. Categorical data were described using both numbers and percentages. To compare different groups for categorical variables, Chi-square tests were used. Numerical data were described with means and standard deviations for normally distributed data. For normally distributed data, comparisons between two independent populations were done using independent $t$-tests; for more than two populations, $F$-tests (ANOVAs) were used. To study the association between two variables, Pearson correlation coefficients were used. Significance test results are quoted as two-tailed probabilities. Significance of the obtained results was judged at the 5\% level.

\section{Results}

The study included 60 patients divided equally among three groups. Twenty eyes of 13 patients with active TED ( 7 with bilateral disease and 6 with unilateral affection and a mean age of $40.75 \pm 10.33$ ) were compared with 20 eyes of 14 patients with inactive disease ( 6 with bilateral affection and 8 with unilateral disease and mean age of $38.5 \pm 9.01$ ). Both groups were compared to 20 eyes of controls. There was a significant difference for age $(p=0.048)$ but not for sex $(p=0.47)$ among the three groups (Table 1). Post hoc analysis showed that the difference was

Table I Comparison of the Three Studied Groups Regarding Demographic Data

\begin{tabular}{|l|c|c|c|c|}
\hline & $\begin{array}{c}\text { Group A } \\
\text { “n=20” }\end{array}$ & $\begin{array}{c}\text { Group B } \\
\text { “n=20” }\end{array}$ & $\begin{array}{c}\text { Group C } \\
\text { “n=20” }\end{array}$ & p-value \\
\hline Age (years) & & & & \\
Range & $26-54$ & $24-56$ & $34-56$ & $0.048 *$ \\
Mean & 40.75 & 38.5 & 45.5 & \\
SD & 10.33 & 9.01 & 7.16 & \\
\hline Sex & & & & 0.47 \\
Male & $7(35.0 \%)$ & $4(20 \%)$ & $8(40 \%)$ & \\
Female & $13(65.0 \%)$ & $16(80 \%)$ & $12(60 \%)$ & \\
\hline
\end{tabular}

Note: * Significant difference. 
only significant between Groups $\mathrm{B}$ and $\mathrm{C}$ for age $(p=0.048)$.

There was a statistically significant difference between the two groups regarding the palpebral fissure height $(p=0.02)$, amount of proptosis $(p=0.008)$, and degree of lagophthalmos $(\mathrm{p}=0.001)$ (Table 2$)$.

The mean CAS differed significantly between Groups $A$ and $B(p=0008)$. The mean OSDI was 40.0 \pm 5.80 , which significantly differed from Group B, 26.5 \pm 5.10 ( $\mathrm{p}=0.021)$. Lipid layer thickness was diminished in the TED groups, with means of $61.4 \pm 5.35$ and $62.3 \pm 4.07$, respectively. Corneal fluorescein staining showed a significant statistical difference (Table 3).

Regarding the meiboscore, there was a statistically significant difference between the two groups in the upper lid $(\mathrm{p}=0.001)$ and the lower lid $(\mathrm{p}=0.001)$ (Table 4$)$.

The duration of the active disease ranged from 4 to 12 months, with a mean of $7.85 \pm 2.54$ months. The inactive disease duration ranged from 16 to 28 months, with a mean duration of 20.8 \pm 3.64 months (Table 5). The mean of Schirmer test I was $7.85 \pm 2.01$ in Group A and $12.45 \pm 1.36$ in Group B, with a statistically significant difference $(\mathrm{p}=0.012)$.

Comparing the three groups, antriperoxidase $\mathrm{Ab}$, antithyroglobulin $\mathrm{Ab}$ and anti-TSH receptors $\mathrm{Ab}$ were significantly different $(p=0.0001)$. The highest values were for Group A and the lowest values were for Group C (Table 6).

Table 2 Comparison Between the Two TED Groups Regarding the Palpebral Fissure Height, Amount of Proptosis, and Degree of Lagophthalmos

\begin{tabular}{|l|c|c|c|}
\hline & $\begin{array}{c}\text { Group A } \\
\text { “n=20” }\end{array}$ & $\begin{array}{c}\text { Group B } \\
\text { “n=20” }\end{array}$ & p-value \\
\hline Palpebral fissure & $10-17$ & $10-16$ & \\
Height & 13.175 & 11.75 & $0.02^{*}$ \\
Range & 2.36 & 1.94 & \\
Mean & & & \\
SD & & $16-25$ & \\
\hline Proptosis (mm) & $17-27$ & 19.15 & $0.008^{*}$ \\
Range & 22.2 & 2.72 & \\
Mean & 2.95 & & \\
SD & & $0-3$ & $0.00 I^{*}$ \\
\hline Lagophthalmos (mm) & $0.5-4$ & 1.08 & \\
Range & 2.3 & 0.79 & \\
Mean & 0.92 & & \\
SD & & & \\
\hline
\end{tabular}

Note: *Significant difference.
Table 3 Comparison Between the Three Studied Groups Regarding OSDI, CAS, NTBUT, LLT, and CFS

\begin{tabular}{|c|c|c|c|c|}
\hline & $\begin{array}{c}\text { Group } \\
\text { A } \\
\text { “n=20” }\end{array}$ & $\begin{array}{c}\text { Group } \\
\text { B } \\
\text { “n=20" }\end{array}$ & $\begin{array}{l}\text { Group } \\
\text { C } \\
\text { “n=20" }\end{array}$ & p-value \\
\hline $\begin{array}{l}\text { OSDI } \\
\text { Range } \\
\text { Mean } \\
\text { SD }\end{array}$ & $\begin{array}{c}28-50 \\
40.0 \\
5.80\end{array}$ & $\begin{array}{c}20-36 \\
26.5 \\
5.10\end{array}$ & $\begin{array}{l}8-14 \\
11.3 \\
1.87\end{array}$ & $0.02 I^{*}$ \\
\hline $\begin{array}{l}\text { CAS } \\
\text { Range } \\
\text { Mean } \\
\text { SD }\end{array}$ & $\begin{array}{l}3-5 \\
3.55 \\
0.60\end{array}$ & $\begin{array}{c}\mathrm{I}-2 \\
\mathrm{I} .4 \\
0.50\end{array}$ & - & $0.0008 *$ \\
\hline $\begin{array}{l}\text { NTBUT (Seconds) } \\
\text { Range } \\
\text { Mean } \\
\text { SD }\end{array}$ & $\begin{array}{l}4-11 \\
6.45 \\
1.79\end{array}$ & $\begin{array}{c}7-13 \\
9.6 \\
1.79\end{array}$ & $\begin{array}{c}10-14 \\
12.3 \\
1.13\end{array}$ & $0.00001 *$ \\
\hline $\begin{array}{l}\text { LLT } \\
\text { Range } \\
\text { Mean } \\
\text { SD }\end{array}$ & $\begin{array}{c}50-70 \\
61.4 \\
5.35\end{array}$ & $\begin{array}{c}56-70 \\
62.3 \\
4.07\end{array}$ & $\begin{array}{c}80-96 \\
87.8 \\
3.82\end{array}$ & $0.013^{*}$ \\
\hline $\begin{array}{l}\text { Corneal fluorescein } \\
\text { staining } \\
\text { Range } \\
\text { Mean } \\
\text { SD }\end{array}$ & $\begin{array}{l}I-4 \\
2.75 \\
1.02\end{array}$ & $\begin{array}{c}0-2 \\
1.1 \\
0.79\end{array}$ & $\begin{array}{l}0-1 \\
0.35 \\
0.49\end{array}$ & $0.00001 *$ \\
\hline
\end{tabular}

Note: *Significant difference.

Abbreviations: CAS; clinical activity score, LLT; lipid layer thickness.

The thyroid antibodies showed strong statistically significant positive correlations with the OSDI and Schirmer test and a statistically significant negative correlation with NITBUT (Table 7).

\section{Discussion}

Thyroid eye disease (TED) is an example of orbital inflammation that is usually related to DED and ocular surface manifestations in $45-85 \%$ of patients. ${ }^{16}$ Several tests are used to diagnose DED using different questionnaires. Among them, some tests can detect tear quantity while others can detect tear quality. A combination of tests should be used since there is no single test which can be used for diagnosing the condition of dry eye. ${ }^{29}$ In this clinical study of 20 eyes of 13 patients with active TED and 20 eyes of 14 patients with inactive disease in comparison with 20 eyes of controls, the results showed that patients with thyroid disorders had prominent dry eye symptoms compared to controls based on the OSDI 
Table 4 Comparison Between the Three Studied Groups Regarding Meiboscore

\begin{tabular}{|l|r|r|r|}
\hline Meiboscore & $\begin{array}{r}\text { Group A } \\
\text { “n=20” }\end{array}$ & $\begin{array}{r}\text { Group B } \\
\text { “n=20” }\end{array}$ & p-value \\
\hline Upper & $3-4$ & $1-2$ & \\
Range & 3.25 & 1.2 & $0.00 I^{*}$ \\
Mean & 0.44 & 0.41 & \\
SD & & & \\
\hline Lower & $2-4$ & $1-2$ & $0.00 I^{*}$ \\
Range & 3.0 & 1.35 & \\
Mean & 0.56 & 0.49 & \\
SD & & & \\
\hline
\end{tabular}

Note: *Significant difference.

Table 5 Comparison Between the Three Studied Groups Regarding Duration, MGD, and Schirmer Test

\begin{tabular}{|c|c|c|c|c|}
\hline & $\begin{array}{r}\text { Group A } \\
\text { “n=20" }\end{array}$ & $\begin{array}{r}\text { Group B } \\
“ n=20 "\end{array}$ & $\begin{array}{r}\text { Group C } \\
“ n=20 "\end{array}$ & p-value \\
\hline $\begin{array}{l}\text { Duration } \\
\text { (months) }\end{array}$ & $4-12$ & $16-28$ & \multirow{4}{*}{ - } & \multirow{4}{*}{$0.000 I^{*}$} \\
\hline Range & 7.85 & 20.8 & & \\
\hline Mean & 2.54 & 3.64 & & \\
\hline SD & & & & \\
\hline \multicolumn{5}{|l|}{ MGD } \\
\hline Negative & II (55\%) & I7(85\%) & I6(80\%) & \multirow[t]{2}{*}{$0.0196 *$} \\
\hline Positive & $9(45 \%)$ & $3(15 \%)$ & $4(20 \%)$ & \\
\hline \multicolumn{5}{|l|}{$\begin{array}{l}\text { Schirmer } \\
\text { test }(\mathrm{mm})\end{array}$} \\
\hline Range & $5-12$ & $10-14$ & $12-15$ & \multirow[t]{3}{*}{$0.012 *$} \\
\hline Mean & 7.85 & 12.45 & 13.7 & \\
\hline SD & 2.01 & 1.36 & 0.92 & \\
\hline
\end{tabular}

Note: *Significant difference.

Abbreviation: MGD, meibomian gland dysfunction.

questionnaire. This is consistent with other published studies. For instance, Eckstein et $\mathrm{al}^{10}$ also found that TED patients had an increased OSDI compared with controls. The current study showed that the median average for the OSDI score was higher in the active TED group than in the inactive group $(40.0 \pm 5.80$ versus $26.5 \pm 5.10)$. Xu et $\mathrm{al}^{20}$ also found that the mean OSDI score was significantly higher in active than inactive TED patients $(\mathrm{p}=0.001)$. However, a study by Tirakunwichcha et $\mathrm{al}^{30}$ found that the prevalence of dry eye in TED was $96 \%$ by TBUT but only $27 \%$ by OSDI, which mandates the objective assessment of dry eye in these patients. TED patients undergo an initial active phase where inflammation, progressive orbital congestion, worsening proptosis and other mechanical changes, including eyelid retraction and lagophthalmos, add to ocular surface damage.

In the study by Wang et $\mathrm{al}^{31}$ comparing active with inactive TED eyes, the measured degrees of lagophthalmos and exophthalmos were significantly higher in active TED eyes ( $\mathrm{p}=00.01$ and $\mathrm{p}<0.001$, respectively). In the current study, we found a significant difference between the two groups, with higher values for exophthalmos, lagophthalmos, and palpebral fissure height in the active TED groups $(\mathrm{p}<0.05)$. When testing the impact of these changes on the ocular surface parameters, Schirmer's test values were significantly reduced in active TED patients compared to those in the inactive group and both groups had significantly decreased values in comparison to the control group $(p<0.05)$. Likewise, In a study by Gürdal $\mathrm{C}$ et $\mathrm{al},{ }^{32}$ patients with TED and dry eye were found to have significantly lower Schirmer test values compared with normal controls. Moreover, in the study by Park et $\mathrm{al}^{33}{ }^{33}$ the active TED cases had greater reduced basal tear secretion compared with inactive TED patients $(\mathrm{p}=0.024)$. The lower Schirmer test values can be explained by the presence of exophthalmos, upper eyelid retraction, and lagophthalmos. Moreover, tear secretion attenuation via impairment of the lacrimal gland due to autoantibodies attacking the receptor of the thyroid-stimulating hormone found in the lacrimal glands adds to the tear volume decrease in TED patients. ${ }^{32}$ The stability of the tear film is also disrupted because of the role of membraneassociated mucin found on the microvilli of cornea and conjunctiva and secretory mucin of the goblet cells of conjunctiva. ${ }^{34}$ In TED, there was a decrease in both the membranes associated and secretory mucin owing to the inflammatory process that leads to evaporative DED and consequently the other ocular surface parameters including tear film instability. In the current study, NITBUT in active and inactive disease was significantly reduced in the active TED patients. Nowak et al found that tear break-up time in TED patients with dry eye (5.84 $\pm 3.31 \mathrm{~s})$ was significantly lower than in controls $(11.4 \pm 3.75 \mathrm{~s})$, suggesting an unstable tear film. ${ }^{16}$ Gupta et $\mathrm{al}^{8}$ showed a decreased tear break-up time (TBUT of less than $10 \mathrm{~s}$ ) in $31 \%$ of their patients.

Corneal and conjunctival vital staining, indicators of ocular surface damage, are a frequent sign in patients with TED. ${ }^{4,35}$ In our study, the CFS showed significantly higher values in active TED indicating more ocular damage in these patients compared with controls $(\mathrm{p}<0.05)$. 
Table 6 Comparison Between the Three Studied Groups Regarding Autoantibodies

\begin{tabular}{|l|c|c|c|c|}
\hline & $\begin{array}{c}\text { Group A } \\
\text { “n=20” }\end{array}$ & $\begin{array}{c}\text { Group B } \\
\text { “n=20” }\end{array}$ & $\begin{array}{c}\text { Group C } \\
\text { “n=20” }\end{array}$ & p-value \\
\hline Antiperoxidase Ab & & & & $0.000 I^{*}$ \\
Range & $15-180$ & $12-58$ & $6-18$ & \\
Mean & 103.4 & 28.3 & 10.5 & \\
SD & 59.64 & 14.37 & 3.98 & \\
\hline Antithyroglobulin Ab & & & & $0.000 I^{*}$ \\
Range & $86-234$ & $34-134$ & $12-52$ & \\
Mean & 161.2 & 89.8 & 33.8 & \\
SD & 43.2 & 25.52 & 12.4 & \\
\hline Anti-TSH receptors & & & & $0.000 I^{*}$ \\
Ab & & & & \\
Range & $2.2-5.2$ & $0.88-3.4$ & $0.2-1.2$ & \\
Mean & 3.77 & 2.05 & 0.32 & \\
SD & 0.92 & 0.74 & 0.07 & \\
\hline
\end{tabular}

Note: *Significant difference.

Table 7 Correlation Between the Thyroid Antibodies and the OSDI, Schirmer Test, and NITBUT

\begin{tabular}{|l|l|r|r|r|}
\hline \multicolumn{2}{|l|}{ Parameters } & OSDI & NTBUT & $\begin{array}{c}\text { Schirmer } \\
\text { Test }\end{array}$ \\
\hline \multirow{2}{*}{$\begin{array}{l}\text { Anti-TSH } \\
\text { receptors AB }\end{array}$} & $\mathrm{r}$ & $0.838^{* *}$ & $-0.745^{* *}$ & $-0.675^{* *}$ \\
\cline { 2 - 5 } & $\mathrm{p}$-value & $0.000 \mathrm{I}$ & $0.000 \mathrm{I}$ & $0.000 \mathrm{I}$ \\
\hline Antiperoxidase AB & $\mathrm{r}$ & $0.709 * *$ & $-0.763^{* *}$ & $-0.637^{* *}$ \\
\cline { 2 - 5 } & $\mathrm{p}$-value & $0.000 \mathrm{I}$ & $0.000 \mathrm{I}$ & $0.000 \mathrm{I}$ \\
\hline Antithyroglobulin & $\mathrm{r}$ & $0.852^{* *}$ & $-0.805^{* *}$ & $-0.723^{* *}$ \\
\cline { 2 - 5 } AB & $\mathrm{p}$-value & $0.000 \mathrm{I}$ & $0.000 \mathrm{I}$ & $0.000 \mathrm{I}$ \\
\hline
\end{tabular}

Note: **Significant correlation.

Meibomian gland dysfunction (MGD) is known to be a major cause of evaporative DED. The ocular surface and eyelid inflammatory response in active TED cases may be directly related to both structural and functional loss in MG. ${ }^{36}$ Kim et al reported that cases having TED suffer from morphological changes in the MG, which correlated with proptosis in addition to palpebral fissure height, which may be related to a decrease of blinking by proptosis and palpebral fissure height that causes decreased excretion for meibum and turns into obstructive MGD. ${ }^{37}$ This compared the meibography score, tear film BUT, and OSDI between Graves' orbitopathy and non-Graves' orbitopathy patients and found that the tear film BUT was shorter and the OSDI and meibography score were higher in the patients' group. ${ }^{37}$
In our study, MGD was found in 16 eyes $(80 \%)$ of the active TED and in 11 (55\%) eyes of the inactive group. The mean meiboscore of $(3.25 \pm 0.44),(3.0 \pm 0.56)$ for the upper and lower eyelids and (1.2 \pm 0.41$),(1.35 \pm 0.49)$ for the active and inactive TED respectively with significantly more severe affection of the active group $(\mathrm{p}=0.001)$. Same findings were observed in Wang et al study ${ }^{31}$ where MGD was significantly more serious in the active TED compared with the inactive TED group ( $\mathrm{p}=0.04)$.

The lipid layer thickness analysis showed no significant difference between TED patients and the control group, and was not significantly related to the CAS $(\mathrm{p}>0.05)$. However, in a study by Wang et al, the subgroup analysis showed that inactive TED eyes were not significantly different compared to non-TED eyes for MG performance and LLT; however, a trend for higher MGD and thicker LLT was shown for both groups. Patients with active TED had more severe MGD but thicker LLT. Which may be explained by the periglandular inflammation of MGs, leading to MGD, but compensatory secretion from residual meibomian glands and lagophthalmosinduced forceful blinking might temporarily release more lipids over the tear film. ${ }^{31}$

Thyroid peroxidase antibody (TPO), thyroid stimulating hormone receptor antibodies (TSHRAb), and thyroglobulin antibody (TGAb) showed strong statistically significant positive correlations with the OSDI and Schirmer test results and a statistically significant negative correlation with NITBUT, which indicates the impact of the disease activity on the symptomatology and severity of dry eye in TED patients. Immunohistochemical analysis showed the presence of thyroid hormone receptor beta (Thrb) in the acinar together with ductal cells of lacrimal glands and in the nuclei of epithelial cells that line the cornea in addition to conjunctival surface. ${ }^{38}$ These receptors are thought to be the target for autoantibodies in TED, and, possibly through aberrant signal transduction, contribute to the reduced aqueous tear production and ocular surface damage in this disorder. ${ }^{10,11}$

\section{Conclusion}

This study revealed ocular surface changes through a comparison among active TED, inactive TED and controls, and documented the high prevalence of DED in these patients, with increased severity during the active phase of the disease and the persistence of dry eye manifestations through the inactive phase due to mechanical factors, namely, lid retraction and proptosis, while mechanical impairment and MGD are the main contributors to DED in the active phase. This result suggests that evaluation of the severity and activity of TED 
and dry eye assessment should be performed together for proper management and treatment of TED patients based on objective evaluation of the ocular surface and the possible role of thyroid antibodies on the severity of dry eye in these patients. We believe this finding deserves further investigation.

\section{Data Sharing Statement}

Available upon request from the corresponding author.

\section{Ethics and Consent}

Informed written consent was obtained from the study participants. Informed written consent was obtained from participants to publish the findings. All procedures performed in studies involving human participants were in accordance with the ethical standards of Alexandria Faculty of Medicine ethics committee and with the 1964 Declaration of Helsinki and its later amendments. Ethical approval was obtained from the ethics committee of Alexandria Faculty of Medicine, Alexandria, Egypt.

\section{Funding}

There is no funding to report.

\section{Disclosure}

The authors reported no conflicts of interest for this work.

\section{References}

1. Bruscolini A, Abbouda A, Locuratolo N, Restivo L, Trimboli P, Romanelli F. Dry eye syndrome in non-exophthalmic graves' disease. Semin Ophthalmol. 2015;30(5-6):372-376. doi:10.3109/ 08820538.2013.874491

2. Smith TJ, Hegedüs L. Graves' Disease. $N$ Engl J Med. 2016;375 (16): $1552-1565$.

3. Achtsidis V, Kozanidou E, Bournas P, Tentolouris N, Theodossiadis PG, Eye D. Clinical disease of tear film, diagnosis and management. Eur Ophthalmic Rev. 2014;08(01):17.

4. Ismailova DS, Fedorov AA, Grusha YO. Ocular Surface Changes in Thyroid Eye Disease. Orbit. 2013;32(2):87-90.

5. Gilbard JP, Farris RL. Ocular surface drying and tear film osmolarity in thyroid eye disease. Acta Ophthalmol (Copenh). 2009;61(1):108-116.

6. Khurana AK, Sunder S, Ahluwalia BK, Malhotra KC. Tear film profile in Graves' ophthalmopathy. Acta Ophthalmol (Copenh). 2009;70(3):346-349.

7. The Definition and Classification of Dry Eye Disease: report of the Definition and Classification Subcommittee of the International Dry Eye Workshop (2007). Ocul Surf. 2007;5(2):75-92.

8. Gupta A, Sadeghi PB, Akpek EK. Occult thyroid eye disease in patients presenting with dry eye symptoms. Am J Ophthalmol. 2009;147(5):919-923.

9. Rocha EM, Mantelli F, Nominato LF, Bonini S. Hormones and dry eye syndrome. Curr Opin Ophthalmol. 2013;24(4):348-355.

10. Eckstein AK, Finkenrath A, Heiligenhaus A, et al. Dry eye syndrome in thyroid-associated ophthalmo- pathy: lacrimal expression of TSH receptor suggests involvement of TSHR-specific autoantibodies. Acta Ophthalmol Scand. 2004;82(3p1):291-297. doi:10.1111/j.1395-3907.2004.00268.x
11. Harris MA, Realini T, Hogg JP, Sivak-Callcott JA. CT dimensions of the lacrimal gland in graves orbitopathy. Ophthal Plast Reconstr Surg. 2012;28(1):69-72. doi:10.1097/IOP.0b013e31823c4a3a

12. Chang TC, Huang KM, Chang TJ, Lin SL. Correlation of orbital computed tomography and antibodies in patients with hyperthyroid graves'disease. Clin Endocrinol (Oxf). 1990;32(5):551-558.

13. Villani E, Viola F, Sala R, et al. Corneal involvement in graves' orbitopathy: an in vivo confocal study. Invest Opthalmol Visual Sci. 2010;51(9):4574.

14. Wu L-Q, Mou P, Chen Z-Y, et al. Altered Corneal nerves in chinese thyroid-associated ophthalmopathy patients observed by in vivo confocal microscopy. Med Sci Monitor. 2019;25:1024-1031.

15. Call CB, Wise RJ, Hansen MR, Carter KD, Allen RC. In vivo examination of meibomian gland morphology in patients with facial nerve palsy using infrared meibography. Ophthal Plast Reconstr Surg. 2012;28(6):396-400.

16. Nowak M, Marek B, Kos-Kudła B, Kajdaniuk D, Siemińska L. Tear film profile in patients with active thyroid orbithopathy. Klin Oczna. 2005;107(7-9):479-482.

17. Alanazi SA, Alomran AA, Abusharha A, et al. An assessment of the ocular tear film in patients with thyroid disorders. Clin Ophthalmol. 2019;13:1019.

18. Rundle F. Management of exophthalmos and related ocular changes in Graves' disease. Metabolism. 1957;6(1):36-48.

19. Wei Y-H, Chen W-L, Hu F-R, Liao S-L. In vivo confocal microscopy of bulbar conjunctiva in patients with Graves' ophthalmopathy. J Formos Med Assoc. 2015;114(10):965-972.

20. Xu N, Huang D, Yang H, Lai Z, Luo Q. Ocular surface characteristics and impression cytology in patients with active versus inactive Thyroid Eye Disease. Eye Sci. 2012;27(2):64-68.

21. Matheis N, Grus FH, Breitenfeld M, et al. Proteomics differentiate between thyroid-associated orbitopathy and dry eye syndrome. Invest Opthalmol Visual Sci. 2015;56(4):2649.

22. Ujhelyi B, Gogolak P, Erdei A, et al. Graves' orbitopathy results in profound changes in tear composition: a study of plasminogen activator inhibitor-1 and seven cytokines. Thyroid. 2012;22(4):407-414.

23. Bahn RS. Graves' ophthalmopathy. $N$ Engl J Med. 2010;362 (8):726-738.

24. Mourits MP, Koornneef L, Wiersinga WM, Prummel MF, Berghout A. van der Gaag R. Clinical criteria for the assessment of disease activity in Graves' ophthalmopathy: a novel approach. $\mathrm{Br}$ J Ophthalmol. 1989;73(8):639-644.

25. Miyata K, Novel Grading A. Method for superficial punctate keratopathy magnitude and its correlation with corneal epithelial permeability. Arch Ophthalmol. 2003;121(11):1537.

26. Arita R, Itoh K, Inoue K, Amano S. Noncontact infrared meibography to document age-related changes of the meibomian glands in a normal population. Ophthalmology. 2008;115(5):911-915.

27. Driver PJ, Lemp MA. Meibomian gland dysfunction. Surv Ophthalmol. 1996;40(5):343-367.

28. Özcura F, Aydin S, Helvaci MR. Ocular surface disease index for the diagnosis of dry eye syndrome. Ocul Immunol Inflamm. 2007;15 (5):389-393.

29. Johnson ME, Murphy PJ. Changes in the tear film and ocular surface from dry eye syndrome. Prog Retin Eye Res. 2004;23(4):449-474.

30. Tirakunwichcha S, Lerdchanapornchai V, Reinprayoon U, Saonanon P, Snabboon T. Prevalence of dry eye disease in autoimmune thyroid disease and the association of dry eye with clinical signs of thyroid associated ophthalmopathy: observational, noncomparative, cross-sectional study. Asian Biomed. 2017;10(2):133-138.

31. Wang C-Y, Ho R-W, Fang P-C, et al. The function and morphology of Meibomian glands in patients with thyroid eye disease: a preliminary study. BMC Ophthalmol. 2018;18(1):90.

32. Gürdal C, Saraç Ö, Genç İ, Kırımlığlu H, Takmaz T. Can i. Ocular surface and dry eye in Graves' disease. Curr Eye Res. 2010;36 (1):8-13. 
33. Park J, Baek S. Dry eye syndrome in thyroid eye disease patients: the role of increased incomplete blinking and Meibomian gland loss. Acta Ophthalmol (Copenh). 2019;97(5):e800-e806.

34. Mantelli F, Argüeso P. Functions of ocular surface mucins in health and disease. Curr Opin Allergy Clin Immunol. 2008;8(5):477-483.

35. Huang D, Luo Q, Yang H, Mao Y. Changes of lacrimal gland and tear inflammatory cytokines in thyroid-associated ophthalmopathy. Invest Opthalmol Visual Sci. 2014;55(8):4935.

36. Hwang HS, Parfitt GJ, Brown DJ, Jester JV. Meibocyte differentiation and renewal: insights into novel mechanisms of meibomian gland dysfunction (MGD). Exp Eye Res. 2017;163:37-45.
37. Kim YS, Kwak AY, Lee SY, Yoon JS, Jang SY. Meibomian gland dysfunction in Graves' orbitopathy. Can J Ophthalmol. 2015;50 (4):278-282.

38. Dias AC, Módulo CM, Jorge AG, et al. Influence of thyroid hormone on thyroid hormone receptor $\beta-1$ expression and lacrimal gland and ocular surface morphology. Invest Ophthalmol Vis Sci. 2007;48 (7):3038-3042.
Clinical Ophthalmology

\section{Publish your work in this journal}

Clinical Ophthalmology is an international, peer-reviewed journal covering all subspecialties within ophthalmology. Key topics include: Optometry; Visual science; Pharmacology and drug therapy in eye diseases; Basic Sciences; Primary and Secondary eye care; Patient Safety and Quality of Care Improvements. This journal is indexed on PubMed

Submit your manuscript here: https://www.dovepress.com/clinical-ophthalmology-journal
Dovepress

Central and CAS, and is the official journal of The Society of Clinical Ophthalmology (SCO). The manuscript management system is completely online and includes a very quick and fair peer-review system, which is all easy to use. Visit http://www.dovepress.com/ testimonials.php to read real quotes from published authors. 